\title{
Inhaler Devices for Chronic Obstructive Pulmonary Disease: Insights from Patients and Healthcare Practitioners
}

\author{
Mathieu Molimard, MD, PhD, and Paul Colthorpe, $\mathrm{PhD}^{2}$
}

\begin{abstract}
Background: The choice of inhaler device for patients with chronic obstructive pulmonary disease (COPD) depends upon multiple attributes. An online survey was devised to assess COPD patients' and healthcare practitioners' (HCPs; physicians and nurses) opinions and preferences for inhaler devices.

Methods: Patients diagnosed with COPD $\geq 6$ months from United States (US), United Kingdom (UK), France, and Germany, and HCPs from the US, UK, France, Italy, and Japan were enrolled to participate in an online quantitative 35 minutes survey. A proprietary analytical tool from Sawtooth Software was used to collect, randomize, and analyze participant opinions and preferences of device attributes, including functionality.

Results: A total of 245 patients (mean age, 60.7 years) completed the survey. Of these, 124 and 121 patients were taking fluticasone/salmeterol, and tiotropium, respectively. Patients cited ease of use, dose recording, and dose capacity (single or multi-dose) as important attributes for the device. Key factors that patients considered would make the device easier to use were fewer steps to operate the inhaler, confirmation that the dose has been taken correctly, easier coordination of breathing manoeuver, and least resistance while inhaling. A total of 504 HCPs (380 physicians and 124 nurses) completed the survey, and cited patient satisfaction and ease of use as the most important attributes when selecting an inhaler device for patients. Dose recording and multi-dose versus singledose designs were given less importance than other attributes such as patient satisfaction and cost by HCPs.

Conclusion: The survey provides important insights into what patients and HCPs consider to be key attributes of an ideal inhaler device for COPD management. Given that patients with COPD self-administer their COPD chronic medication and need to deliver the correct dose, it is important to consider these insights for the appropriate management of COPD.
\end{abstract}

Key words: chronic obstructive pulmonary disease, healthcare practitioners' preference, inhaler devices, patient preference

\section{Introduction}

C Hronic OBSTRUCTIVE PUlmonary DISEASE (COPD) is a complex disease with increasing morbidity and mortality. ${ }^{(1)}$ It is estimated that by year 2020, COPD will be the third leading cause of mortality worldwide. ${ }^{(2)}$ COPD represents a significant societal and economic burden throughout the world. ${ }^{(1,3)}$ Current strategy for the management of COPD recommends the use of inhaled medication for relieving symptoms and preventing complications and exacerbations. ${ }^{(1)}$

Despite advancement in medical treatment, poor adherence remains a major challenge in the management of $\mathrm{COPD},{ }^{(4)}$ and adversely impacts health outcomes, quality of life, and healthcare expenditures. ${ }^{(5)}$ Between $40 \%$ and $60 \%$ of patients with COPD do not adhere to the prescribed regimen. ${ }^{(6)} \mathrm{Fac}-$ tors impacting adherence in COPD may be associated with patients (health beliefs, cognitive ability, co-morbidities, and psychological condition), drug treatment (method of drug administration, dosing regimen, polypharmacy, and side effects), and societal factors (access to medication, social support, device training, and follow-up). ${ }^{(6)}$

Efficient delivery of inhaled medication is essential for the success of COPD therapy. ${ }^{(1,7)}$ The inhaler device may contribute to optimal drug delivery ${ }^{(8)}$ and also impact patient adherence. ${ }^{(9)}$ A wide range of inhaler devices are available, including pressurized metered dose inhalers (pMDIs), dry

\footnotetext{
${ }^{1}$ Département de Pharmacologie, CHU de Bordeaux, Universite Bordeaux, INSERM U657, Bordeaux Cedex, France.

${ }^{2}$ Novartis Pharma AG, Basel, Switzerland.
} 
powder inhalers (DPIs), nebulizers, and soft mist inhalers (SMI). ${ }^{10}$ Each type of device has its own advantages and disadvantages. ${ }^{(10)}$

When considered independently of drug class, choice of inhaler device depends on availability and cost of inhalation treatment, clinical setting, age of the patient, dosing regimen, physician and patient preference, and ability of the patient to use the inhaler. ${ }^{(7,9,11)}$ Patient satisfaction, and consequently adherence, largely depend on the patients' attitude towards the inhaler and their ability to use the device. ${ }^{(7,12)}$ However, studies have shown that patients often struggle with various attributes of different inhalers, ${ }^{(13)}$ and poor technique is common regardless of the device used. ${ }^{(14)}$

It is important to understand which device attributes may influence physicians' and patients' preference towards COPD therapy and drive adherence. Here, we present the results of a device choice survey, which aimed to assess the opinions and preferences of patients and healthcare practitioners (HCPs; physicians and nurses) for inhaler devices.

\section{Materials and Methods}

\section{Participants}

The survey was conducted by $\mathrm{P} \backslash \mathrm{S} \backslash \mathrm{L}$ Research Europe in COPD patients and HCPs (physicians, both general practitioners and pulmonologists; and nurses). Patients aged $\geq 40$ years who had been diagnosed with COPD for $\geq 6$ months participated from the United States (US), the United Kingdom (UK), France, and Germany. Physicians who participated were from the US, UK, France, Italy, and Japan. They had been practicing for 3-34 years, treating 40-100 patients per month, had spent $20 \%-75 \%$ time treating patients, and had personally trained at least one COPD/asthma patient per month on inhaler technique. Nurses in the survey were from the US and UK. They were responsible for the management of COPD/asthma patients, had been involved in the education and training of COPD/asthma patients for 3-34 years, and had trained at least one patient per month.

\section{Assessments/Questionnaires}

Online quantitative surveys of around 35 minutes were completed by patients with COPD and asthma (March 31April 30, 2010) and HCPs (January 5-29, 2010). Initial data were reported at European Respiratory Society (ERS) congress in 2011, ${ }^{(15)}$ and this article presents further more detailed analysis from COPD patients. The patient questionnaire was divided into four sections: (1) patients' current situation including specialization of the consulting physician, frequency of visits to physician, severity of the disease, etc.; (2) conjoint analysis exercise, ${ }^{(16)}$ which narrowed down the patients' preference for eight attributes of an ideal inhaler (see below), measured the relative importance of each attribute, and analyzed the attributes with number of doses per day, an attribute driven by drug, separately; (3) patient preferences, which identified the most important and difficult attributes of current inhaler, patients' situation, and inhaler attributes on a scale of 1-7; and (4) demographic questions.

The HCP questionnaire covered both COPD- and asthmarelated questions (approximately 50\% each). In this article, we present results from the completed COPD questions. The HCP questionnaire was divided into four sections: (1) pre- scribing/practice behavior; (2) conjoint analysis exercise that narrowed down HCPs' preference for 11 attributes (see below) of an ideal inhaler, measuring the relative importance of each attribute, and analyzing the attributes with total cost and treatment class separately; (3) other priorities, such as ranking of attributes that are important for ease of use; and (4) demographic questions.

Attributes evaluated in patients included doses carried, ease of use, dose confirmation, dose recording, size of inhaler, technology, whether disposable or recyclable, and ready to inhale cue. Number of doses per day (although driven by drug, rather than device) was also included in the evaluation. Attributes evaluated in HCPs were type of inhaler and doses carried, screening requirements, patient feedback, ease of use and training, dose confirmation, dose recording, size of inhaler, compliance evidence, efficient delivery to the lung, technology, disposable or recyclable device, cost and treatment class. The details of these attributes are presented in Supplementary Tables S1 and S2.

\section{Analysis}

Sawtooth Software's adaptive choice-based conjoint analysis $(\mathrm{ACBC})^{(17)}$ and choice-based conjoint analysis $(\mathrm{CBC})^{(18)}$ products were used to collect, randomize, and analyze responses about choice across various attributes and functions of inhalers. Attributes were analyzed individually for their importance. Each attribute was described by attribute level statements to which the respondent indicated their degree of agreement (Supplementary Tables S1 and S2). For example, within the size of inhaler attribute, the attribute levels were (1) smallest size, (2) middle size, and (3) largest size. Based on individual responses, utility values for attributes levels, expressing positive or negative impact, were derived. The higher the utility value for a given attribute level, the more value this attribute level holds for respondents compared to the other levels of the same attribute. A positive utility value for an attribute level indicated that to be more desirable for a respondent than an attribute level with a negative utility value. For instance, a utility value of +100 was three times stronger than a utility value of -50 .

Using the utility value for the individual attribute levels, the relative importance of an attribute was calculated. For each attribute, a larger spread from the highest to lowest utility values indicated a higher importance to respondents versus other attributes with comparatively narrow spread of utility values. Relative importance of overall device attributes versus compounding factors such as number of the doses per day, cost, and drug class was also calculated. Relative attribute importance scores were expressed as percentages. Data collection and analyses were not associated with, nor related to, any specific attribute of marketed brands or devices.

\section{Results}

\section{Characteristics of patient participants}

A total of 245 COPD patients (US, 62; UK, 62; Germany, 59; France, 62) participated in the survey. Mean age of patients and duration of COPD was 60.7 years, and 8.3 years, respectively. The majority of patients had moderateto-severe airflow limitation, with the most common symptoms being shortness of breath, chest tightness, and chronic cough. A total of 124 patients were taking fluticasone/ 
Table 1. Patient Characteristics

\begin{tabular}{|c|c|c|c|c|c|c|}
\hline & $\begin{array}{l}\text { Overall } \\
\mathrm{n}=245\end{array}$ & $\begin{array}{c}U S \\
\mathrm{n}=62\end{array}$ & $\begin{array}{c}E U \\
\mathrm{n}=183\end{array}$ & $\begin{array}{c}U K \\
\mathrm{n}=62\end{array}$ & $\begin{array}{c}\text { Germany } \\
\mathrm{n}=59\end{array}$ & $\begin{array}{c}\text { France } \\
\mathrm{n}=62\end{array}$ \\
\hline Mean age, years & 60.7 & 64.3 & 59.5 & 61.5 & 60.2 & 56.9 \\
\hline Mean number of years since first COPD diagnosis, years & 8.3 & 8.5 & 8.2 & 7.9 & 8.9 & 7.9 \\
\hline \multicolumn{7}{|l|}{ Level of severity diagnosed,*\% } \\
\hline Mild & 12 & 7 & 13 & 15 & 13 & 11 \\
\hline Moderate & 42 & 43 & 44 & 40 & 58 & 36 \\
\hline Severe & 30 & 28 & 30 & 32 & 21 & 36 \\
\hline Very severe & 6 & 8 & 5 & 3 & 3 & 7 \\
\hline Unknown & 10 & 14 & 8 & 10 & 5 & 10 \\
\hline \multicolumn{7}{|l|}{ Type of HCP visits, \% } \\
\hline Primary care physician & 45 & 41 & 46 & 76 & 46 & 16 \\
\hline Pulmonologist & 41 & 54 & 36 & 10 & 20 & 79 \\
\hline Internal medicine specialist & 9 & 3 & 11 & 2 & 32 & 0 \\
\hline Other & 5 & 1 & 7 & 12 & 2 & 5 \\
\hline Mean number of times visited in the last 12 months & 4 & 3 & 4 & 4 & 5 & 3 \\
\hline \multicolumn{7}{|l|}{ Current symptoms, \% } \\
\hline Shortness of breath on doing brisk activity & 80 & 87 & 78 & 82 & 63 & 87 \\
\hline Chronic cough & 54 & 42 & 58 & 43 & 66 & 66 \\
\hline Mucus production & 55 & 65 & 52 & 47 & 48 & 61 \\
\hline Constant shortness of breath & 38 & 48 & 34 & 38 & 36 & 29 \\
\hline Chest tightness & 36 & 26 & 39 & 39 & 43 & 34 \\
\hline Occasional acute/severe attacks ( $\leq 1$ per year) & 32 & 21 & 35 & 30 & 46 & 30 \\
\hline Frequent acute/severe attacks ( $>1$ per year) & 24 & 21 & 25 & 26 & 20 & 30 \\
\hline
\end{tabular}

*GOLD 2009 criteria.

COPD, chronic obstructive pulmonary disease; GOLD, the global initiative for chronic obstructive lung disease; HCPs, healthcare practitioners.

A

\begin{tabular}{|c|c|c|c|c|}
\hline & Mild/Stage I & Moderate/Stage II & Severe/Stage III & $\begin{array}{l}\text { Very severe/ } \\
\text { Stage IV }\end{array}$ \\
\hline 76 & 31 & 34 & 22 & 13 \\
\hline
\end{tabular}

Mean no of patients on
maintenance therapy/month
$\square$ LABA alone $\square$ LAMA alone $\square$ Fixed Dose Combination (FDC) ICS / LABA $\square$ LAMA + LABA $\square$ FDC ICS/LABA + LAMA $\square$ Other

Mild/Stage I treatment

Moderate/Stage II treatment

Severe/Stage III treatment

Very severe/Stage IV treatment

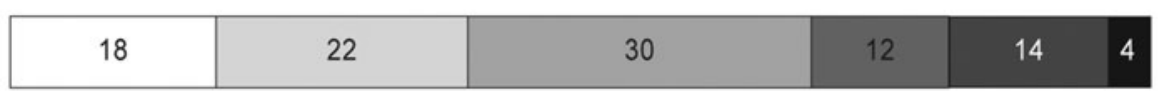

\begin{tabular}{|l|l|l|l|l|}
\hline 9 & 15 & 28 & 17 & 30 \\
\hline
\end{tabular}

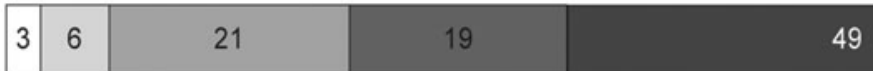

61

FIG. 1. Prescribing/managing behavior of HCPs. (A) HCP's patient population with COPD: Physicians were asked, of the patients that you treat for COPD with maintenance therapy in an average month, how many are at each of the following stages of COPD? Nurses were asked, of the patients that you personally manage for COPD in an average month, how many of these patients that you are managing are on a maintenance therapy? (B) Prescribing behavior of physicians by degree of airflow limitation. FDC, fixed dose combination; ICS, inhaled corticosteroids; LABA, longacting $\beta$ agonist; LAMA, long-acting muscarinic antagonist. 
salmeterol $\left(\operatorname{Advair}^{\circledR}\right)$, and 121 patients were taking tiotropium $\left(\right.$ Spiriva $\left.^{\circledR}\right)$ as a maintenance therapy. In patients taking fluticasone/salmeterol, a multi-dose DPI (mDPI) was most commonly used (53\%), followed by a pMDI (40\%) or both $(7 \%)$. Patients taking tiotropium were using a singledose DPI inhaler (93\%), SMI $(6 \%)$, or both $(1 \%)$. Patients were under the care of a primary care physician (45\%), specialist respiratory physician (pulmonologist; 41\%), internal medicine specialist $(9 \%)$ or other healthcare providers $(5 \%)$. Other patient characteristics are presented in Table 1.

\section{Characteristics of HCP participants}

A total of 504 HCPs (US, 138; Japan, 76; UK, 138; Italy, 76; France, 76; total 380 physicians and 124 nurses) pro- vided responses to the COPD survey. Among physicians, 230 were general practitioners and 150 were respiratory specialists. COPD and asthma accounted for roughly $20 \%$ of their total prescription load. The physicians had shared practice with one to five other physicians. They were treating a mean of 76 COPD patients per month with maintenance therapy, and most of their patients had mild-to-moderate airflow limitation. Prescribing patterns by degree of airflow limitation are presented in Figure 1. It was observed in this survey, that in contrast with the global initiative for chronic obstructive (GOLD) guidelines recommendation, patients with mild COPD (Stage I GOLD) were being treated with inhaled corticosteroids/long-acting $\beta$ agonist combination. Nurse participants had worked with one to five physicians, and had trained the patients on the use of inhaler devices.

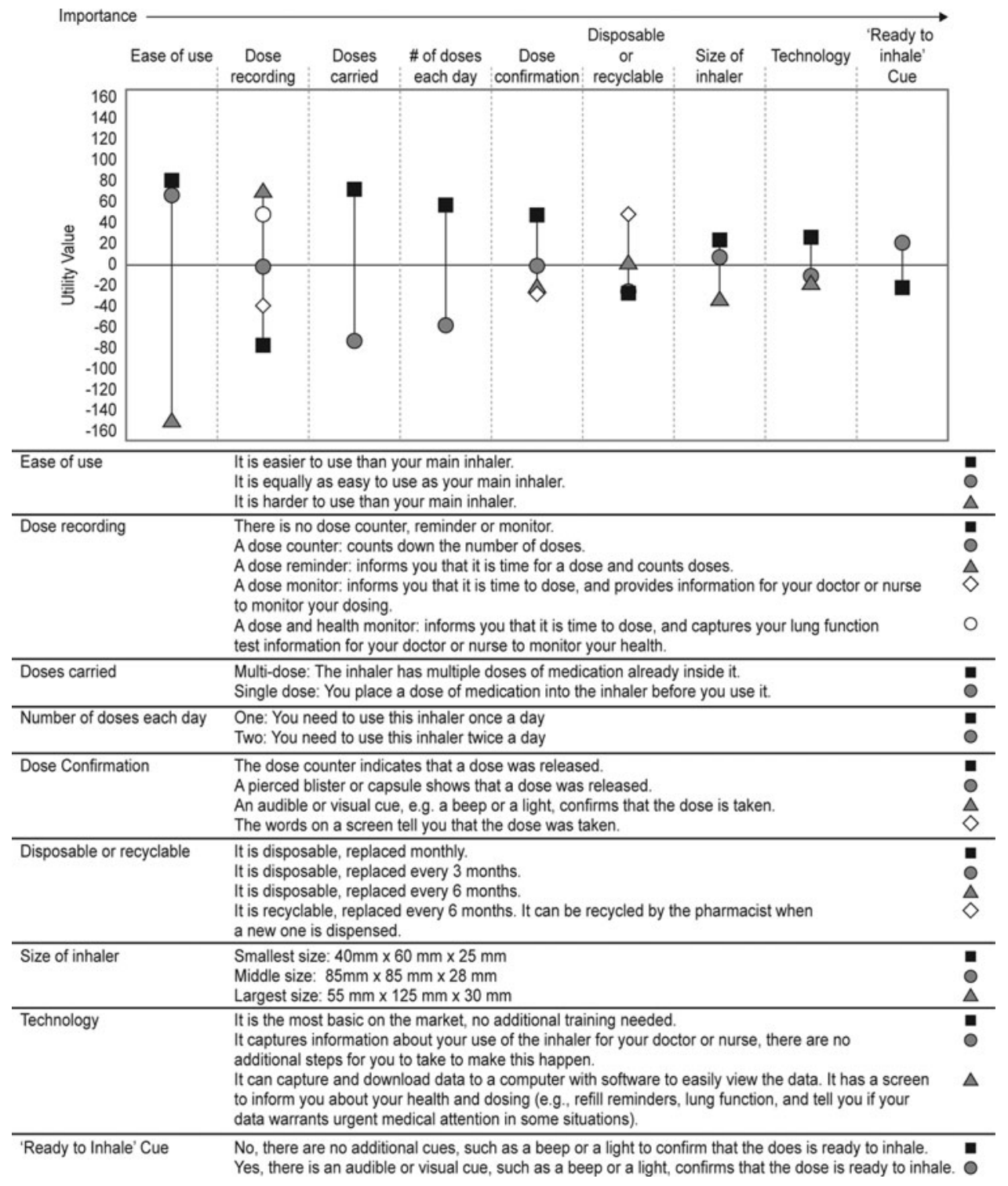

FIG. 2. Choice utility values derived for patients (with number of doses each day). Positive choice utility value for a given attribute level indicates a more desirable attribute, whereas a negative utility value of the attribute level indicates a less desirable attribute. For each attribute, the larger the spread from the highest to lowest utility values, the higher that attribute's importance. 


\section{Conjoint analysis of utility values} and relative attribute importance

Among patients, ease of use and then dose recording and doses carried were important attributes. These attributes showed the largest range from the highest to lowest utility values. For ease of use, dose recording and doses carried attributes, the highest utility values were given to easier to use than their main (current) inhaler, dose reminder, and multi-dose attribute levels, respectively (Fig. 2). Conjoint analysis indicated that the attributes pertaining to the device characteristics accounted for $88 \%$ of the relative importance that patients placed on the device versus the number of doses each day, which accounted for only $12 \%$ of the relative importance (Fig. 3A). Relative importance of device attributes versus importance of number of doses each day was the highest in the US (94\%) and the lowest in France (84\%).

Among HCPs, patient satisfaction was the most important attribute for all regions except Japan, where size of inhaler, proof of compliance, and dose recording (dose reminder) were the three most important attributes of an inhaler device (Fig. 4 and Supplementary Fig. S1). Ease of use was the second most important attribute, followed by either class or cost for all regions, except France and Japan. In France, patient satisfaction, recyclability, and drug class were considered the most important characteristics that an inhaler should have. Overall in Europe, recyclability of an inhaler was considered more important than cost. Dose recording and dose carried (multi-dose versus single-dose designs), which were important attributes of the inhaler for the patients, were given less importance by HCPs (Fig. 4 and Supplementary Fig. S1).

Many HCPs felt that patient satisfaction and preference was more important than any other attribute of an inhaler device, with the main reason given for this being an asso- ciation with improvement in adherence. HCPs felt the least acceptable attributes were patient dissatisfaction and subsequent request for an alternative, monthly disposal, and being hard to use/teach, as these increased inconvenience and reduced compliance. Conjoint results indicated that the device attributes account for $79 \%-85 \%$ of the relative importance versus cost $(6 \%-10 \%)$ and treatment class $(7 \%-$ $11 \%$; Fig. 3B).

\section{Patient opinions and preferences}

Patients reported being satisfied with their current inhalers, giving a rating of 5.5 on a scale of 1-7 (Fig. 5). Overall, patients were certain that they had been taking the dose fully and correctly with a rating of 5.3 on a scale of 1-7 (Fig. 5). Approximately $37 \%$ patients (43\% US and 35\% Europe [34\% UK; 33\% Germany; and 38\% France]) usually checked the dose counter (if present) every time they took their medication. Patients preferred to know that they had taken the right dose by either feeling the medication working in their lungs $(36 \%)$ or by visual confirmation $(31 \%)$. A total of $20 \%$ of patients gave priority to hearing confirmation that they had received a dose, and 13\% rated feeling the dose by taste or sensation.

Requests for changing inhaler were infrequent. The most common reasons for changing the inhaler were that the medication was not working $(48 \%)$ or that the previous device was not functioning (23\%). A further $18 \%$ responded that their previous device was hard to use, $6 \%$ reported that previous inhaler was no longer available, and $5 \%$ provided other reasons for changing inhaler.

The three main inhaler attributes that the patients considered to be most important were ease of use/convenience, efficacy, and inhaler size which were given primary importance
A

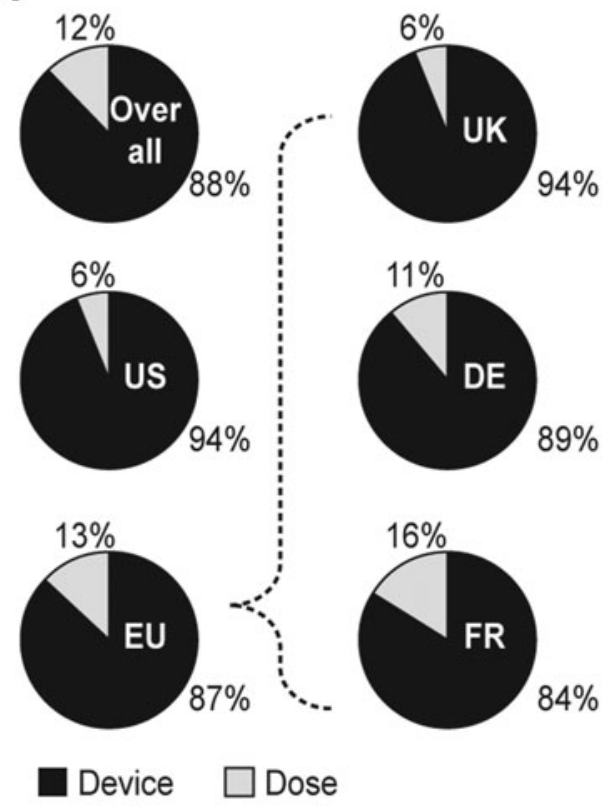

B

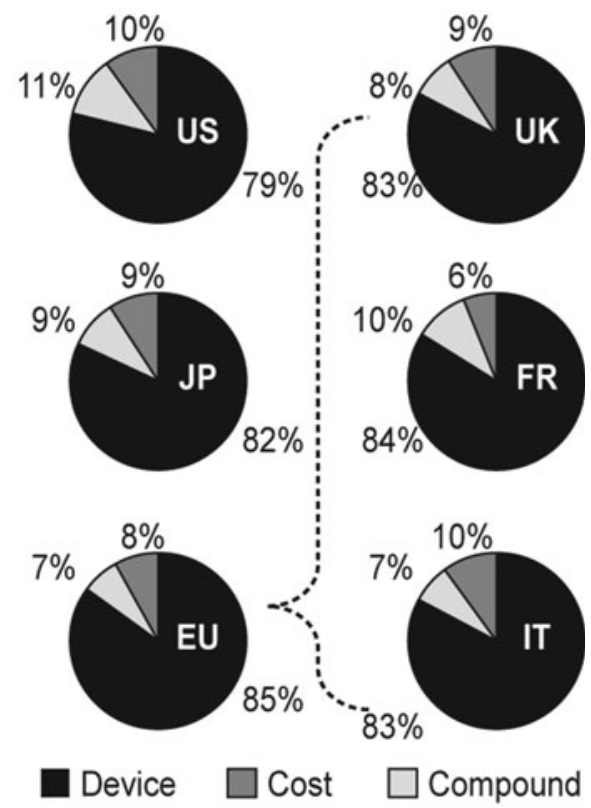

FIG. 3. Relative importance of device attributes. (A) Patient survey. (B) HCP survey. Relative importance of device attributes in patients and HCPs surveys. DE, Germany; EU, Europe; FR, France; IT; Italy; JP, Japan; UK, United Kingdom; US, United States. 

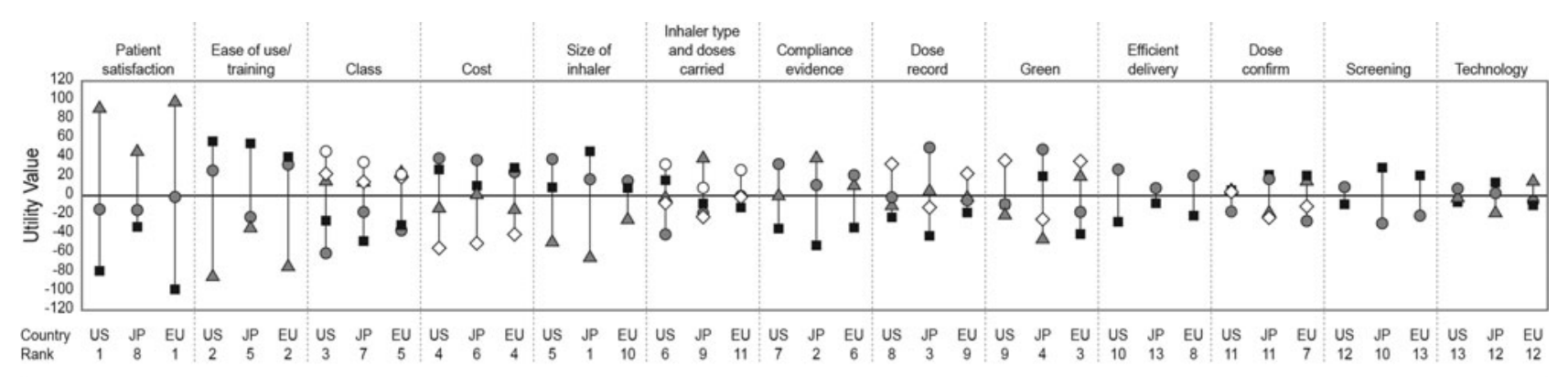

\begin{tabular}{|c|c|c|c|c|}
\hline Patient satisfaction & $\begin{array}{l}\text { Patients are dissatisfied with the inhaler and prefer or request another. } \\
\text { Patients are neither satisfied nor dissatisfied. } \\
\text { Patients are satisfied with the inhaler and prefer or request it over others. }\end{array}$ & & & $\stackrel{\circ}{\Delta}$ \\
\hline Ease of use and training & $\begin{array}{l}\text { It is easier to use and teach than other inhalers. } \\
\text { It is equally as easy to use and teach as other inhalers. } \\
\text { It is harder to use and teach than other inhalers. }\end{array}$ & & & $\begin{array}{l}\ddot{\circ} \\
\Delta\end{array}$ \\
\hline Class of Compound & $\begin{array}{l}\text { LABA alone } \\
\text { LAMA alone } \\
\text { Fixed Dose Combination (FDC) ICS / LABA } \\
\text { LAMA + LABA } \\
\text { FDC ICS/LABA + LAMA }\end{array}$ & $\begin{array}{l}\text { Total cost of the inhaler } \\
\text { with the compound }\end{array}$ & $\begin{array}{l}\text { The total cost is } 10 \% \text { less than lowest cost of inhalers with compound. } \\
\text { The total cost is Equal to the lowest cost inhalers with compound. } \\
\text { The total cost is } 10 \% \text { more than lowest cost inhalers with compound. } \\
\text { The total cost is } 20 \% \text { more than lowest cost inhalers with compound. }\end{array}$ & $\begin{array}{l}\Delta \\
\Delta\end{array}$ \\
\hline Size of inhaler & \multicolumn{3}{|l|}{$\begin{array}{l}\text { Smallest size: } 40 \mathrm{~mm} \times 60 \mathrm{~mm} \times 25 \mathrm{~mm} \\
\text { Middle size: } 85 \mathrm{~mm} \times 85 \mathrm{~mm} \times 28 \mathrm{~mm} \\
\text { Largest size: } 55 \mathrm{~mm} \times 125 \mathrm{~mm} \times 30 \mathrm{~mm}\end{array}$} & $\begin{array}{l}- \\
\Delta\end{array}$ \\
\hline $\begin{array}{l}\text { Inhaler type and } \\
\text { doses carried }\end{array}$ & \multicolumn{3}{|l|}{$\begin{array}{l}\text { Dry powder inhaler (DPI) - single dose with capsules } \\
\text { Dry powder inhaler (DPI) - single dose with blisters } \\
\text { Dry powder inhaler (DPI) - multi-dose } \\
\text { Metered dose inhaler (MDI) } \\
\text { The medication is offered in both MDI and DPI inhalers for choice }\end{array}$} & $\begin{array}{l}\text { : } \\
\stackrel{0}{\Delta} \\
\diamond \\
0\end{array}$ \\
\hline Compliance evidence & \multicolumn{3}{|l|}{$\begin{array}{l}\text { No evidence is avalable on compliance improvement. } \\
\text { The ease in the inhaler features imply compliance and that patients are motivated to use it. } \\
\text { Proof of compliance is available in peer-reviewed articles. }\end{array}$} & $\stackrel{\square}{\triangle}$ \\
\hline Dose recording & \multicolumn{3}{|c|}{$\begin{array}{l}\text { A dose counter: counts down the number of doses. } \\
\text { A dose reminder. informs the patient that it is time for a dose and counts doses. } \\
\text { A dose monitor. informs the patient that it is time to dose, and graphs data for healthcare professional monitoring of compliance. } \\
\text { A dose and health monitor. informs the patient that it is time to dose, captures lung function data, and graphs it for healthcare professional monitoring of health and compliance. }\end{array}$} & $\begin{array}{l}\ddot{\circ} \\
\stackrel{\Delta}{\Delta}\end{array}$ \\
\hline Green & \multicolumn{3}{|c|}{$\begin{array}{l}\text { It is disposable, replaced monthly. } \\
\text { It is disposable, replaced every } 3 \text { months. } \\
\text { It is disposable, replaced every } 6 \text { months. } \\
\text { It is recyclable, replaced every } 6 \text { months. It can be recycled by the pharmacist when a new one is dispensed. }\end{array}$} & $\begin{array}{l}\text { : } \\
\stackrel{\circ}{\circ}\end{array}$ \\
\hline Efficient delivery to the lung & \multicolumn{3}{|c|}{$\begin{array}{l}\text { It delivers the drug as efficiently as the average inhaler. } \\
\text { It delivers the drug more efficiently than the average inhaler, reducing the amount of active drug needed in each dose. }\end{array}$} & - \\
\hline Dose confirmation & \multicolumn{3}{|l|}{$\begin{array}{l}\text { The dose counter indicates that a dose was released. } \\
\text { A pierced blister or capsule shows that a dose was released. } \\
\text { An audible or visual cue, e.g. a beep or a light, confirms that the dose is taken. } \\
\text { The words on a screen tell the patient that the dose was taken. }\end{array}$} & $\begin{array}{l}\text { : } \\
\stackrel{\circ}{\Delta} \\
\Delta\end{array}$ \\
\hline Screening requirements & \multicolumn{3}{|l|}{$\begin{array}{l}\text { Screening is not required to determine if the patient is able to use it. } \\
\text { Screening is required to determine if the patient is able to use it. }\end{array}$} & " \\
\hline Technology & \multicolumn{3}{|c|}{$\begin{array}{l}\text { It is the most basic on the market, no additional patient training needed. } \\
\text { It can capture patient use data for the healthcare professional to download, no additional patient training needed. } \\
\text { It can capture, download and graph patient use data. It has a screen to inform the patient and it has software for the healthcare professional to easily view the data. }\end{array}$} & $\begin{array}{l}\text { " } \\
\triangle\end{array}$ \\
\hline
\end{tabular}

FIG. 4. Choice utility values (with class and cost attributes) derived for HCPs in US, Europe, and Japan. A positive choice utility value for a given attribute level indicates a more desirable attribute, whereas a negative utility value of the attribute level indicates a less desirable attribute. For each attribute, the larger the spread from the highest to lowest utility values, the higher that attribute's importance. Of the 13 attributes, the importance of each attribute has been ranked for each country/region. EU, Europe; ICS, inhaled corticosteroids; JP, Japan; LABA, long-acting $\beta$ agonist; LAMA, long-acting muscarinic antagonist; US, United States.

by $66 \%, 29 \%$, and $27 \%$ patients, respectively. Patients stated that an inhaler with attributes such as least number of steps to operate, easier way to tell that the dose has been taken correctly, easier coordination of breathing in and out at the right times, and with least resistance when inhaling would make it easier to use. Patients rated these features with a score of 5.8, 5.7, 5.7, and 5.6, respectively, on a scale of 1-7 (Fig. 6A).

Most adherent patients in COPD were older, with shortness of breath, taking a large number of medications for their conditions, and seek visual dose confirmation. Patients with severe COPD, who were taking most medications for their conditions, were mostly on Spiriva ${ }^{\circledR}$ HandiHaler, were somewhat satisfied, somewhat adherent, and least interested in ease of use features. In contrast, moderate COPD patients, who were mostly taking Spiriva ${ }^{\circledR}$ Handihaler, were most satisfied and most adherent. They were interested in easy-touse features of the inhaler. Moderate-severe patients suf- fering from chronic bronchitis taking least medication were not dominated by any specific inhaler (an almost equal number of patients were on Spiriva ${ }^{\circledR}$ and Advair ${ }^{\circledR}$ [Diskus or pMDI]) and they were somewhat satisfied, and most adherent with Spiriva ${ }^{\circledR}$ Handihaler. These patients were highly interested in easy to use features.

\section{HCP opinions and preferences}

According to HCPs, the main reason for the patients changing their inhaler in the previous month, was patients' inability to use the device correctly $(22.6 \%$ [8.4\% patients failed to extract full dose; $6.4 \%$ patients did not understand operating steps, $5.6 \%$ patients had dexterity issues; $2.2 \%$ other issues]), followed by changes in medication (6.2\%), inhaler being too cumbersome $(4.2 \%)$, inhaler failure or breakage (1.8\%), and other general dissatisfaction (3.0\%). HCPs' ratings in order of importance for making a device 


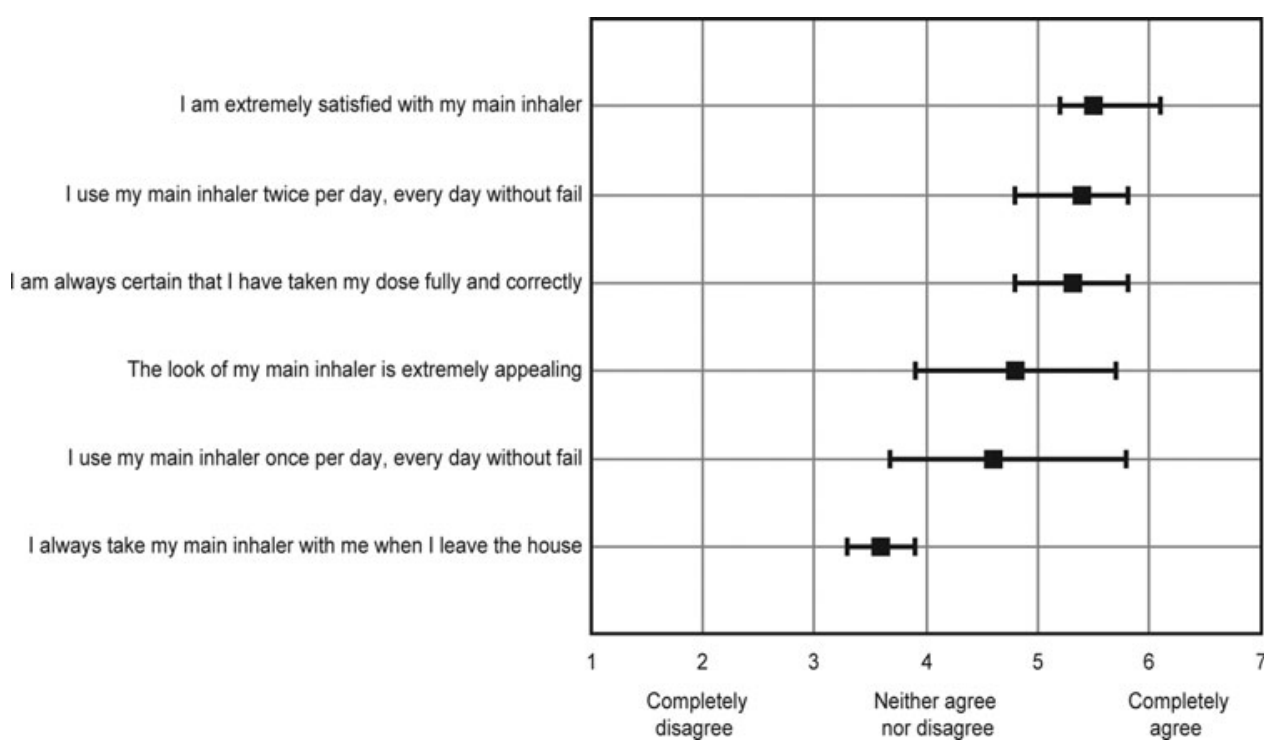

FIG. 5. Level of agreement with key statements about patient's specific behaviours and inhaler characteristics. Patients were asked: On a scale of 1 to 7 , where $1=$ completely disagree, and $7=$ completely agree, how strongly do you agree with each of the following statements?

easier to use were less steps to operate it, breath-actuation, and the least force required to operate it (Fig. 6B).

One of the considerations from HCPs was capturing/ downloading of patient data for assisting/engaging noncompliant patients. HCPs believed that technology is most appealing when related to adherence. HCPs would prefer inhalers that capture data electronically to monitor compliance $(30 \%-42 \%)$ and help patients engage with the management of COPD (16\%-55\%; Supplementary Fig. S2).

\section{Discussion}

This survey was designed to assess patients' and HCPs' opinions and preferences for inhaler devices. It revealed ease of use as one of the most important device attributes for both patients and HCPs. This finding is in line with previous studies. ${ }^{(19,20)}$ Patient satisfaction and ease of use were the most important attribute for HCPs, and were the main reasons why HCPs selected an inhaler for their patients. The survey showed that HCPs favor devices that match patient preference and drive adherence. According to the HCPs, devices that were easy to use, and provided assurance to patients that they had taken the full dose correctly promoted patient adherence. In contrast, dose counter and multiple dosing versus single-dosing capability were considered less important than patient satisfaction, class, cost, etc. by HCPs. Since different attributes have been considered for patients and HCPs, a direct comparison is difficult.

Both patients and HCPs stated that breath actuation was an important attribute. It eliminated the requirement to coordinate breathing and activation manoeuvres. Dry powder inhalers do not require this coordination, but due to their design, they are associated with some resistance to inhalation. ${ }^{(21-24)}$ Patients in this study stated that low resistance was an important attribute, which is consistent with a previous report that decreased resistance increased the acceptability of an inhaler. ${ }^{(24)}$
In this study, HCPs stated that the most frequent reason for patients changing their inhaler in the previous month was inability to use the device correctly (22.6\%) rather than change in medication $(6.2 \%)$. Errors in handling the inhaler are common in patients with COPD. ${ }^{(14,25)}$ One study documented that nine out of 10 patients did not use their inhaler correctly, ${ }^{(6)}$ which impacted adherence ${ }^{(26)}$ and led to the suboptimal management of COPD. Moreover, the use of multiple inhalers needed for different medications in combination therapy (when disease progressed) confused the patients and further reduced compliance. ${ }^{(12,27)}$

Patient-related issues, which impact adherence to medication, include inhaler preference or satisfaction level, co-morbidities and physical issues, cognitive and mood disorders, ${ }^{(26,28-30)}$ whereas physician-related issues include lack of awareness and knowledge on how to effectively instruct patients in proper inhaler use. ${ }^{(31,32)}$ Often, HCPs prescribe inhalers based on available/preferred drugs, without considering whether the patient can effectively use the device, ${ }^{(33)}$ potentially impacting adherence to the prescribed therapy.

HCPs believe that technology is most appealing for the purpose of aiding compliance and capturing/downloading of patient data is important for assisting/engaging noncompliant patients. However, technology features, which require additional training, are negatively perceived by HCPs (as shown in Fig. 4). Technology should not decrease patient satisfaction or decrease HCP-perceived ease of use, or increase the level of patient training needs.

Overall, this survey highlights some of the key factors that determine patients' device preference and HCPs' perception of relevant attributes. Improved device selection based on individual patient requirements could help make COPD treatment more acceptable to patients leading to more successful COPD disease management. ${ }^{(34)}$ 
A

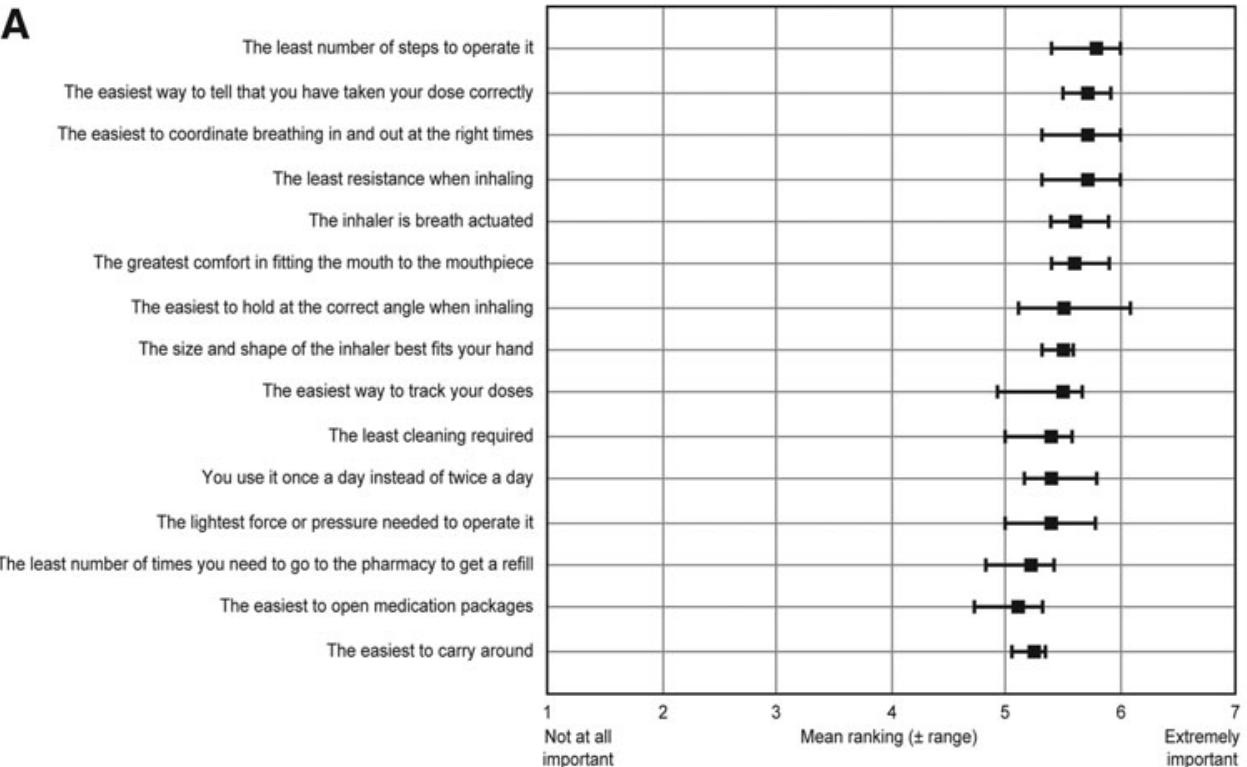

B

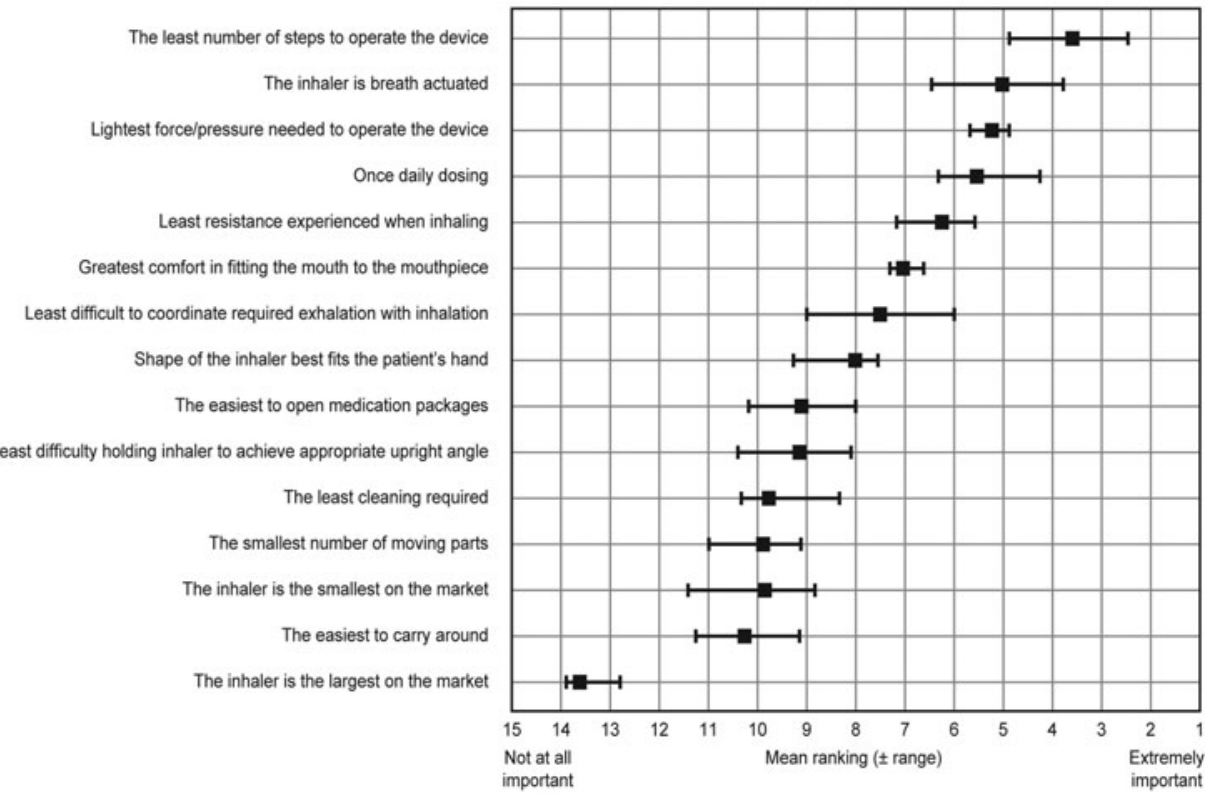

FIG. 6. Most desirable attributes of inhaler that would make it easier to use. (A) Ranking by patients: Patients were asked: On a scale of 1 to 7 , where $1=$ not important at all, and $7=$ extremely important, how important do you believe the following attributes are in making the inhaler easier to use than other inhalers? (B) Ranking by HCPs: HCPs were asked: Please rank the attributes with regard to how important you consider them to be in terms of ease of use and teaching versus other inhalers.

\section{Conclusion}

In conclusion, this study demonstrated that for patients, ease of use is a key characteristic of the ideal inhaler device. For HCPs, patient satisfaction and ease of use were the most important attributes when selecting an inhaler device. According to patients, minimal steps to operate, breath-actuated mechanism, and confirmation of dose delivery, would make an inhaler easier to use. Dose recording and multi-dose versus single-dose designs were given less importance than other attributes such as patient satisfaction and cost by HCPs.

\section{Acknowledgments}

The survey was sponsored by Novartis Pharma AG. Basel, Switzerland. The authors acknowledge Arvind Semwal (Novartis Healthcare Pvt. Ltd., India) for medical writing support and Thomas McMurray (CircleScience, United Kingdom) for editorial support.

Authors actively participated in the preparation of the manuscript and provided critical review at each step. PC was involved with study design and data interpretation. MM was involved in data interpretation and provided critical inputs for the preparation of manuscript. 
Funding: The survey was sponsored by Novartis Pharma AG. Basel, Switzerland.

\section{Author Disclosure Statement}

MM is employed by the University of Bordeaux and the University Hospital of Bordeaux. He has acted as consultants in the field of asthma, COPD, and other topics with most pharmaceutical companies, including AstraZeneca, BMS, GSK, Mundipharma, Novartis Pharma, Pfizer, and Stallergen. The Department of Pharmacology relies partly on research contracts with the pharmaceutical industry for its funding. PC is an employee of Novartis Pharma AG, and hence eligible for Novartis stock options.

\section{References}

1. Global Initiative for Chronic Obstructive Lung Disease (GOLD). Global Strategy for the Diagnosis, Management and Prevention of Chronic Obstructive Pulmonary Disease. Available from: http://www.goldcopd.org. 2013. Accessed August 26, 2013.

2. World Health Organization. Chronic obstructive pulmonary disease (COPD). Available from http://www.who.int/ respiratory/copd/en/. 2013. Accessed July 10, 2013.

3. Mannino DM, and Kiriz VA: Changing the burden of COPD mortality. Int J Chron Obstruct Pulmon Dis. 2006;1: 219-233.

4. George J, Kong DC, and Stewart K: Adherence to disease management programs in patients with COPD. Int J Chron Obstruct Pulmon Dis. 2007;2:253-262.

5. DiMatteo MR: Variations in patients' adherence to medical recommendations: A quantitative review of 50 years of research. Med Care. 2004;42:200-209.

6. Restrepo RD, Alvarez MT, Wittnebel LD, Sorenson H, Wettstein R, Vines DL, Sikkema-Ortiz J, Gardner DD, and Wilkins RL: Medication adherence issues in patients treated for COPD. Int J Chron Obstruct Pulmon Dis. 2008;3: 371-384.

7. Dolovich MB, Ahrens RC, Hess DR, Anderson P, Dhand R, Rau JL, Smaldone GC, and Guyatt G: Device selection and outcomes of aerosol therapy: Evidence-based guidelines: American College of Chest Physicians/American College of Asthma, Allergy, and Immunology. Chest. 2005;127: 335-371.

8. Bateman ED: Improving inhaler use in COPD and the role of patient preference. Eur Respir Rev. 2005;14: $85-88$.

9. Vincken W, Dekhuijzen PR, Barnes P: The ADMIT series-Issues in inhalation therapy. 4) How to choose inhaler devices for the treatment of COPD. Prim Care Respir J. 2010;19:10-20.

10. Newman SP: Inhaler treatment options in COPD. Eur Respir Rev. 2005;14:102-108.

11. Anderson P: Patient preference for and satisfaction with inhaler devices. Eur Respir Rev. 2005;14:109-116.

12. Makela MJ, Backer V, Hedegaard M, and Larsson $\mathrm{K}$ : Adherence to inhaled therapies, health outcomes and costs in patients with asthma and COPD. Respir Med. 2013;107: 1481-1490.

13. Stevens N: Inhaler devices for asthma and COPD: choice and technique. Prof Nurse. 2003;18:641-645.
14. Molimard M, Raherison C, Lignot S, Depont F, Abouelfath A, and Moore N: Assessment of handling of inhaler devices in real life: An observational study in 3811 patients in primary care. J Aerosol Med. 2003;16:249-254.

15. Molimard M, and Girogi-Vigo K: How can we improve patient use of inhaler devices in COPD? [Poster]Molimard M, Girogi-Vigo K. European Respiratory Society Annual Congress, 24-28 September, Amsterdam,The Netherlands. 2011.

16. Sawtooth Software. Conjoint Analysis (http://www.saw toothsoftware.com/solutions/conjoint_analysis). 2010. Accessed August 1, 2013.

17. Sawtooth Software. Adaptive choice-based conjoint analysis (http://www.sawtoothsoftware.com/products/acbc). 2010. Accessed August 1, 2013.

18. Sawtooth Software. Choice-based conjoint analysis (http:// www.sawtoothsoftware.com/products/cbc). 2010. Accessed August 1, 2013.

19. Schulte M, Osseiran K, Betz R, Wencker M, Brand P, Meyer $\mathrm{T}$, and Haidl P: Handling of and preferences for available dry powder inhaler systems by patients with asthma and COPD. J Aerosol Med Pulm Drug Deliv. 2008;21:321328.

20. Hodder R, and Price D: Patient preferences for inhaler devices in chronic obstructive pulmonary disease: Experience with Respimat Soft Mist inhaler. Int J Chron Obstruct Pulmon Dis. 2009;4:381-390.

21. Clark AR, and Hollingworth AM: The relationship between powder inhaler resistance and peak inspiratory conditions in healthy volunteers-Implications for in vitro testing. J Aerosol Med. 1993;6:99-110.

22. Lavorini F, Magnan A, Dubus JC, Voshaar T, Corbetta L, Broeders M, Dekhuijzen R, Sanchis J, Viejo JL, Barnes P, Corrigan C, Levy M, and Crompton GK: Effect of incorrect use of dry powder inhalers on management of patients with asthma and COPD. Respir Med. 2008;102:593604.

23. Wilson DS, Gillion MS, and Rees PJ: Use of dry powder inhalers in COPD. Int J Clin Pract. 2007;61:2005-2008.

24. van der Palen J, Klein JJ, Kerkhoff AH, and van Herwaarden CL: Evaluation of the effectiveness of four different inhalers in patients with chronic obstructive pulmonary disease. Thorax. 1995;50:1183-1187.

25. Fink JB, and Rubin BK: Problems with inhaler use: A call for improved clinician and patient education. Respir Care. 2005;50:1360-1374.

26. Bourbeau J, and Bartlett SJ: Patient adherence in COPD. Thorax. 2008;63:831-838.

27. Yu AP, Guerin A, Ponce de LD, Ramakrishnan K, Wu EQ, Mocarski M, Blum S, and Setyawan J: Therapy persistence and adherence in patients with chronic obstructive pulmonary disease: Multiple versus single long-acting maintenance inhalers. J Med Econ. 2011;14:486-496.

28. Geller DE: Comparing clinical features of the nebulizer, metered-dose inhaler, and dry powder inhaler. Respir Care. 2005;50:1313-1321.

29. Melani AS, Bracci LS, and Rossi M: Reduced peak inspiratory effort through the Diskus((R)) and the Turbuhaler((R)) due to mishandling is common in clinical practice. Clin Drug Investig. 2005;25:543-549.

30. Jarvis S, Ind PW, and Shiner RJ: Inhaled therapy in elderly COPD patients; Time for re-evaluation? Age Ageing. 2007; 36:213-218. 
31. Broeders ME, Sanchis J, Levy ML, Crompton GK, and Dekhuijzen PN: The ADMIT series-Issues in inhalation therapy. 2. Improving technique and clinical effectiveness. Prim Care Respir J. 2009;18:76-82.

32. Hanania NA, Wittman R, Kesten S, and Chapman KR: Medical personnel's knowledge of and ability to use inhaling devices. Metered-dose inhalers, spacing chambers, and breath-actuated dry powder inhalers. Chest. 1994;105: $111-116$.

33. Nikander K: Challenges and opportunities in respiratory drug delivery devices. Expert Opin Drug Deliv. 2010;7: 1235-1238.

34. Yawn BP, Colice GL, and Hodder R: Practical aspects of inhaler use in the management of chronic obstructive pulmonary disease in the primary care setting. Int $\mathrm{J}$ Chron Obstruct Pulmon Dis. 2012;7:495-502.
Received on March 20, 2014

in final form, August 5, 2014

Reviewed by: Bruce Rubin

Federico Lavorini

Address correspondence to:

Professor Mathieu Molimard Département de Pharmacologie CHU de Bordeaux University Bordeaux-INSERM, U657 33076 Bordeaux Cedex

France

E-mail: mathieu.molimard@u-bordeaux.fr 